\title{
Finding the Sweet Spot: The Intersection of Technology, Pedagogy, and Mathematics in Preservice Training
}

\author{
Barbara Martin $^{1}$, Karlee Stapf $^{1} \&$ Tessa Kanturek ${ }^{1}$ \\ ${ }^{1}$ Southern Illinois University Edwardsville, Edwardsville, USA \\ Correspondence: Dr. Barbara Martin, Southern Illinois University Edwardsville, Edwardsville, IL 62026, USA. \\ E-mail: barmart@siue.edu
}

Received: March 15, 2021

Accepted: April 9, 2021

Online Published: April 21, 2021

doi:10.5430/irhe.v6n1p15

URL: https://doi.org/10.5430/irhe.v6n1p15

\begin{abstract}
The purpose of this research was to look critically at successful technology integration in teacher preparation programs. Researchers used the Technology, Pedagogy and Content Knowledge (TPACK) framework developed by Mishra and Koehler (2006) to provide a lens that quantitatively and qualitatively examines student knowledge. Data was collected for three years to see if the development of TPACK had increased in pre-service teachers. Results from the study found that the pre-service teachers developed pedagogical knowledge more than any other constructs, followed by content knowledge, and finally technological knowledge. This knowledge can help us learn how to instruct future teachers more seamlessly in methods for integrating technology into the K-12 classroom, without compromising the content or pedagogy. These three areas (TK, CK, and PK) can be developed independently, but in order for TPACK to truly evolve and successful learning to happen in the classroom, having overlap between these separate content knowledge constructs is imperative.
\end{abstract}

Keywords: technology integration, teacher preparation, TPACK, pedagogy knowledge, technology knowledge, content knowledge

\section{Intro: Background and Review of Literature}

Due to our technologically advanced society, there are many options to integrate some of that technology into the classroom. Teacher candidates are fluent in everyday technologies such as cell phones and tablets, but implementing these into the classroom in authentic and content-rich ways can be more challenging. To help pre-service teachers incorporate technology in a meaningful way, researchers often rely on the Technological, Pedagogical and Content Knowledge (TPACK) framework which originated from Shulman's (1986) framework. Shulman's original framework looked at the overlap of content and pedagogy in lessons and how they were both needed for successful instruction. Since technology has evolved and been infused into our everyday lives, the framework changed as well in order to include pedagogical knowledge (PK), technological knowledge (TK), and content knowledge (CT) (Koehler, Mishra, Cain, 2013). TPACK occurs at the critical juncture, or "sweet spot" where all three of these separate constructs of knowledge overlap. By developing these three areas, teacher candidates found that their future lessons will be more engaging and influential for their students.

The TPACK framework helps teacher candidates think critically about infusing their instructional skills (pedagogy) with technology and subject specific content (Gür \& Karamete, 2015). For this project, teacher candidates are asked to intentionally address technological knowledge, content knowledge, and pedagogical knowledge as they plan lessons. Technology knowledge (TK) involves awareness of a variety of technological tools, materials, and programs. Content knowledge (CK) includes knowing the facts, concepts, theories, and principles for a specific subject. For example, elementary math concepts can range from skills and strategies for solving addition, subtraction, multiplication, division, measurement or geometric problems. Pedagogical knowledge (PK) is considered knowledge about the process of learning and practices or methods of teaching. There are three other overlaps where two of the knowledge constructs are being addressed (TCK, TPK, and PCK), but according to Mishra and Koehler (2006) successful technology integration lies at the critical center overlap of each of the constructs (TPACK).

The TPACK framework is used as a format for integrating technology into the classroom because this framework helps teachers figure out a specific type of technology that can be woven into the curriculum while using the proper pedagogy to help the students use the technology accurately. Strategically choosing technology that can be paired with 
mathematical concepts will help students be more engaged while helping them understand difficult or abstract mathematical content. The TPACK framework will help pre-service teachers figure out content-specific material and technology while using the best teaching and research-based instructional strategies.

The initial step of research for this study was doing a thorough review of current literature. During this review of literature, researchers analyzed a comprehensive list of articles with keywords: TPACK, technology integration, and pre-service teachers. An annotated bibliography was then composed so each part of the themes in the literature reviews could be broken down. The purpose of the review of literature was to gain a baseline understanding of the current research of TPACK development in teacher candidates, and investigate the common themes within the scholarly literature. Several larger themes emerged as the current research was examined and will be explained in the following paragraphs.

\subsection{Literature Review Theme One: Developing TPACK}

One of the important themes that emerged during a review of current literature was the topic of development of TPACK. It is widely supported that this development happens the more pre-service teachers are exposed to the TPACK framework (Wetzel, Buss, Foulger, \& Lindsey, 2014; Jamieson-Proctor, Albion, Finger, Cavanagh, Fitzgerald, Bond, \& Grimbeek, 2013; Hsu, 2012; Bate, Day, Macnish, 2013; Keser, Yilmaz, F., Yilmaz, R., 2015; Mouza, Karchmer-Klein, Nandakumar, Ozden, Hu, 2014; Tondeur, van Braak, Sang, Voogt, Fisser, Ottenbreit-Leftwich, 2012). The more exposure a pre-service teacher has to the idea of incorporating technology in meaningful and purposeful ways, the more comfortable they will feel using these techniques in their own classroom. The discussion of the TPACK framework can potentially take place in any teacher preparation course. Two examples are a math methods class and technology-intensive class for teacher preparation programs. The earlier a pre-service teacher is exposed to these different TPACK constructs, the more practice they can have with these techniques, increasing the amount of learning (Yigit, 2014).

Exposure to TPACK through teacher preparation courses is essential to helping teacher candidates understand and develop this framework. However, current research on TPACK found that teacher candidates also need to have more instructional opportunities to fine-tune, practice and build confidence in their technology integration skills (Mudzimiri, 2012). Providing more planning and teaching opportunities within the elementary schools would build pre-service teachers experience and confidence because they would be able to apply the skills into a real life setting (Wetzel, Buss, Foulger, Lindsey, 2014; Mudzimiri, 2012). These additional teaching opportunities helped pre-service teachers become prepared to teach in today's ever-changing educational environments.

\subsection{Literature Review Theme Two: Incorporating TPACK in Math Methods Courses}

The review of current TPACK literature also uncovered a theme related to TPACK integration into math methods courses within teacher preparation programs. In order to incorporate TPACK in the math methods class, the subject-specific math standards should first be outlined. Next, content-specific technologies should be chosen to support the methods taught so pre-service teachers can begin building their confidence and knowledge of tools and strategies that are appropriate for the elementary math classroom.

After technology is integrated into the math methods course, the current literature suggests that pre-service teachers need role models who are current practicing teacher educators to help strengthen their knowledge of successful integration (Tondeur, van Braak, Sang, Voogt, Fisser, \& Ottenbreit-Leftwich, 2012). Research suggests that a role model can have a strong effect on the development of teacher candidate interest and knowledge towards successful technology use in their own future classroom (Lunenberg, M. Lunenberg K., Anja F. \& Anja S., 2007). Positive role models can help improve self-efficacy in pre-service teachers and increase their pedagogical repertoire (Keser, Yilmaz, F., \& Yilmaz, R. 2015; Lunenberg, M. Lunenberg K., Anja F. \& Anja S., 2007).

A review of current research also determined that collaboration with peers can help support pre-service teachers to develop TPACK. Coursework that requires teacher candidates to explore, communicate, plan and implement content-rich technology lessons can improve confidence and beliefs in their capacity to take on the challenge of innovative technology integration (Niess, 2018). Knowledge-building communities help future teachers share and brainstorm innovative and original ideas while being supported in a synergistic setting. When pre-service teachers collaborate with each other, they expand their thoughts, build their self-efficacy, and challenge each other to further develop the connection between the theory and pedagogy. All of these tactics can be incorporated into the math methods course to further technological, pedagogical, and content knowledge in future teachers. 


\subsection{Literature Review Conclusion}

In conclusion, the initial step of research for this study was doing a thorough review of current literature where researchers analyzed a comprehensive list of articles about TPACK, technology integration, and pre-service teachers. The purpose of the review of literature was to gain a baseline understanding of the current research of TPACK development in teacher candidates, investigate the common themes within the scholarly literature and determine areas of research need in the field of technology integration.

Through the review of literature it was determined that while there were many articles on building self-efficacy in technology integration and the importance of role models as well as ample practical implementation time, there were very few articles about specific technology integration experiences such as our study. This study helps those in teacher preparation begin to understand the importance of thoughtfully crafted projects that provide teacher candidates with intentional technology integration opportunities to plan, teach and reflect using content specific technologies. In a sense, this study pulled together many of the suggested strategies found in the literature review such as plenty of time for practical implementation and thoughtful coursework that requires teacher candidates to explore, communicate, plan and implement content-rich technology lessons (Niess, 2018). The specifics on the study, coursework assignments and student reflection of the experience are all detailed below.

\section{The Study}

To help build upon the research reviewed above, the following study was developed to further investigate the integration of technology into a teacher preparation math methods course. The two research questions we asked for this project included:

R1: To what extent were each of the TPACK constructs developed in the Elementary Education Math Methods Technology Integration Project?

R2: What evidence of each of the TPACK constructs was found within the four assignments?

These questions helped guide us when evaluating our data to make sure TPACK was being illustrated and how prevalent it was in the math methods course. Two secondary objectives that informed the research: 1) How is developing TPACK beneficial to teacher candidates? 2) Which of the four assignments requirements contributed to TPACK development the most?

\section{Setting}

The study was conducted at Midwest State University (MSU; pseudonym), a university with a population of approximately 14,000 students. Geographically, MSU is located in a smaller rural area close to large metropolitan city. MSU's Department of Teaching and Learning enrolls undergraduate students approximately 200 students annually. MSU's Department of Teaching and Learning has been continuously accredited by the National Council for Accreditation of Teacher Education (NCATE) and Council for the Accreditation of Educator Preparation (CAEP). MSU prepares undergraduates in early childhood elementary, middle, secondary, and special education. At the time of this study, the MSU Elementary Education program boasts a 93\% graduation rate.

\section{Data Collection}

The data for this study was collected over three years from the MSU math methods course for elementary education majors (called teacher candidates or pre-service teachers). The teacher candidates in this program were required to complete a technology assignment as part of the math methods course objectives. The math methods class was a course that focuses on how students can meaningfully incorporate pedagogy and mathematics content into the classroom with researched-based strategies. This class also requires teacher candidates to teach math to elementary students in the school setting, reflect on their instructional strategies by recording their teaching and practice teaching in a virtual learning environment that simulated an elementary classroom.

The technology assignment given during the math methods course specifically expected pre-service teachers to first explore a technology, reflect and share information with peers on a digital bulletin board called Padlet, design a lesson plan that incorporates the assigned technology and finally make a digital presentation demonstrating the technology. The technologies that the pre-service teachers were able to choose from included: Dash and Dot, Minecraft, Lego WeDo, 3D Printer, Ozobot, Webquest, Geometer's Sketchpad, Tinkerplots, Desmos, Scratch, Solar Robot, and Recycle Robot. Making a lesson plan was the most crucial step of this project because it required pre-service teachers to start making overlaps with the techniques learned in the methods course to how the technology can be implemented into the elementary classroom. Lesson plans provided pre-service teachers and opportunity to draw an abundance of connections between the assigned technology, Common Core State Standards, proactive pedagogy strategies, and 
common content misconceptions. This step allowed pre-service teachers to think about research-based teaching strategies and ways to incorporate these strategies into their lesson.

The final part of the assignment required teacher candidates to individually reflect on the assignment experience and how confident they felt with technology integration. The reflections allowed students to look back on the project as a whole, especially the development of their TPACK with this lesson and consider goals for future instruction. Reflecting is an essential part of teaching because it allows teachers to analyze what can be improved and highlights the exceptional parts of the lesson. The data generated from the pre-service reflections illustrated that contemplating the lesson after it happened was where teacher candidates were most able to communicate their TPACK knowledge and growth. This project as a whole allowed pre-service teachers to start picturing how to seamlessly infuse technology into their lessons in a creative and meaningful way.

At the conclusion of the project, researchers reviewed all of the documents submitted for the assignment for evidence of the TPACK constructs. This included printed Padlets, handouts, lesson plans and reflections. The coding process involved researchers establishing coding norms and then independently reviewing all data for evidence of the TPACK constructs. The qualitative research methods we used were descriptive and labeled a sentence that showed an element of TPACK with a T, P, C, PC, TP, TC, or TPACK depending on how it correlated with the various TPACK components. Descriptive coding provided a categorical topic label to assist the researcher in organizing and making conclusions (Saldana, 2015). For this qualitative research we did a lot of data collection and analysis that will help us substantiate our methods for coding. According to Mack et al. (2005) "the coding of data involves interacting with data, using techniques to develop those concepts into terms of their properties and dimensions" (p. 66). Researchers then met to discuss independently assigned codes for alignment and compiled numbers based on each TPACK construct which established the final quantitative data set.

To further inform the quantitative data, a qualitative analysis was used with quotes from the student reflections that illustrate specific components of the TPACK constructs. These qualitative excerpts provide specific examples of how teacher candidates began to internalize TPACK information and the process of technology integration. It's important to note that this project has IRB approval exempt status because the assignment was required for the course and all student work was anonymous and/or names were removed.

\section{Results}

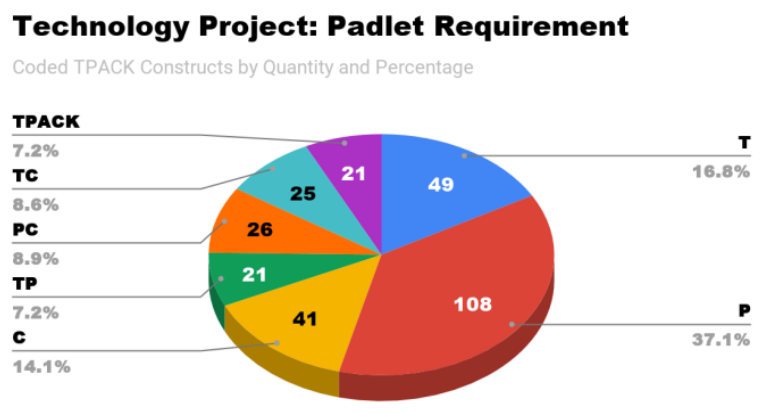

Figure 1. Padlet requirement 


\section{Teachnology Project: Reflection}

Coded TPACK Constructs by Quantity and Percentage

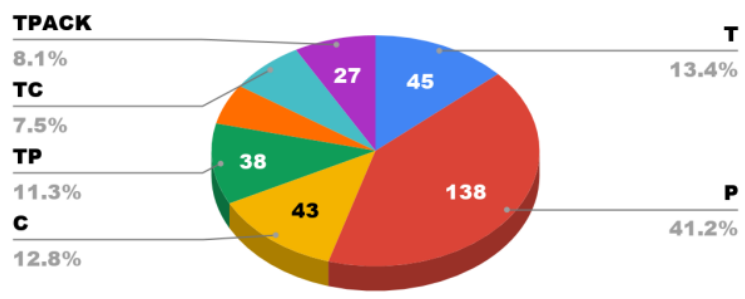

Figure 2. Reflection requirement

\section{Technology Project: Handout}

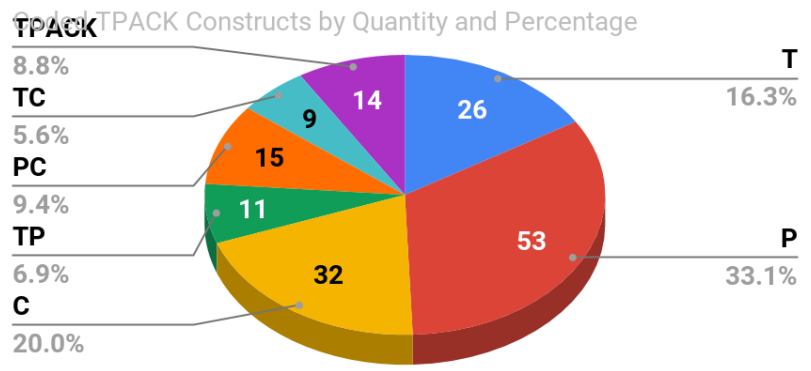

Figure 3. Handout requirement

\section{Technology Project: Lesson Plan Requirement}

Coded TPACK Constructs by Quantity and Percentage

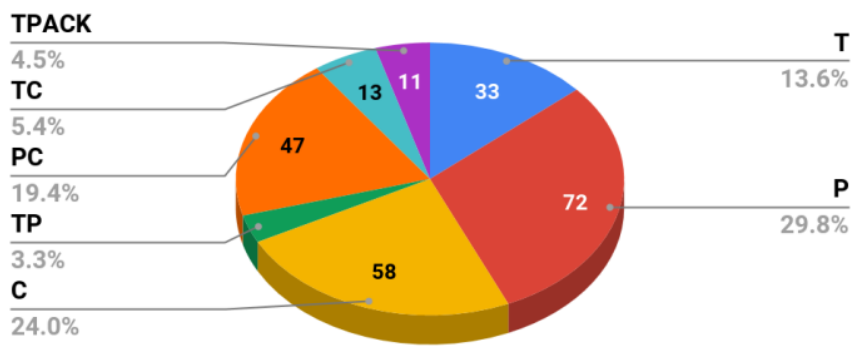

Figure 4. Lesson plan requirement 


\section{Break Down of TPACK Categories}

Coded TPACK Constructs by Quantity and Ordered from Greatest to Least

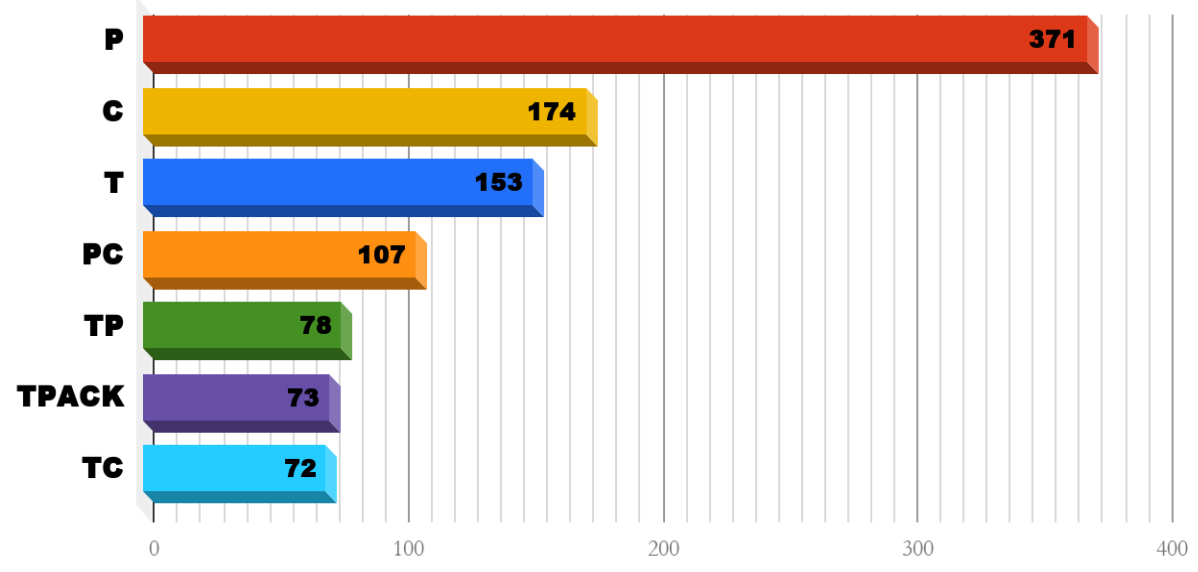

Figure 5. Break down of TPACK Categories

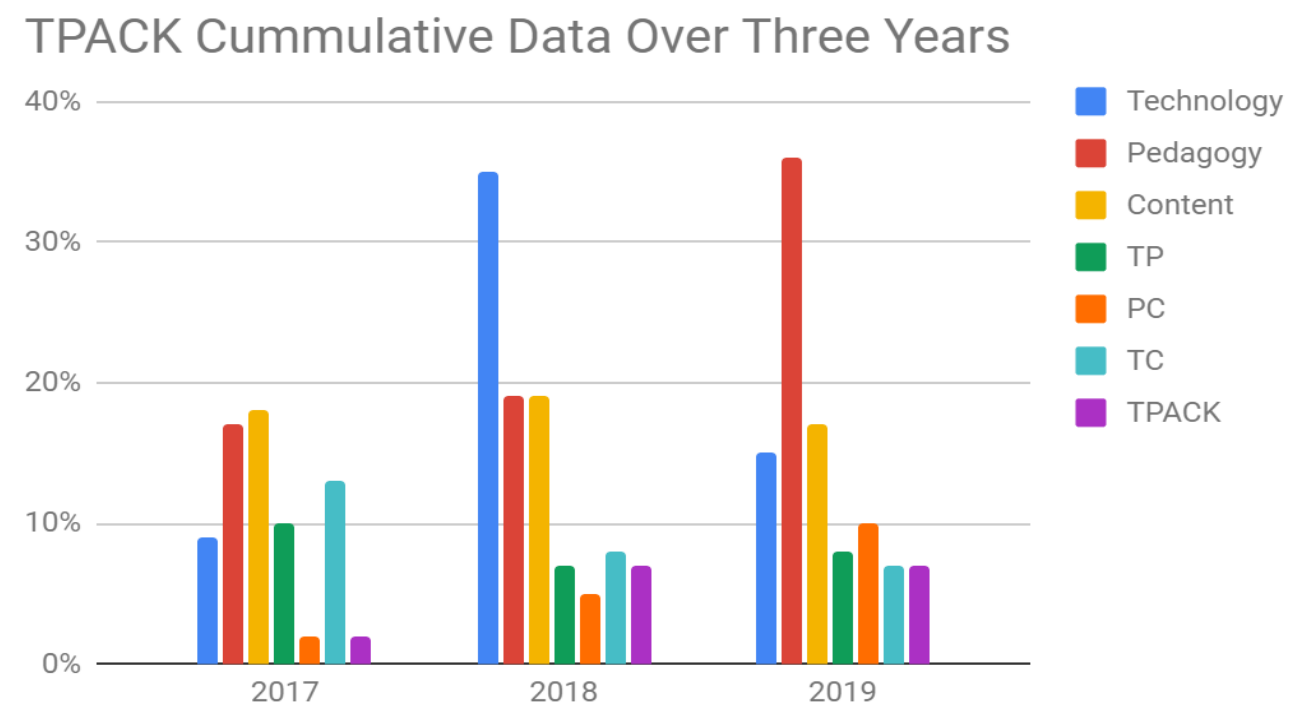

Figure 6. Cumulative TPACK data over three years

\section{Quantitative Data Analysis}

The data graphs illustrate the quantitative analysis of evidence of each TPACK constructs through each part of the technology integration project. The pre-service teachers in this course were able to demonstrate their ability to use TPACK in their writing that will translate into their future classroom. The construct that was most evident within the 
Padlet requirement of the assignment was Pedagogy (37.1\%), Technology (16.8\%), Content (14.1\%), Technology/ 1Pedagogy (7.2\%), Pedagogy/Content (8.9\%), Technology/Content (8.6\%), and TPACK (7.2\%). The handout had percentages of Pedagogy (33.1\%), Technology (16.3\%), Content (20.0\%), Technology/Pedagogy (6.9\%), Pedagogy/Content $(9.4 \%)$, Technology/Content $(5.6 \%)$, and TPACK $(8.8 \%)$. The lesson plan had percentages of Pedagogy (29.8\%), Technology (13.6\%), Content (24.0\%), Technology/Pedagogy (3.3\%), Pedagogy/Content (19.4\%), Technology /Content (5.4\%), and TPACK (4.5\%). The reflection had percentages of Pedagogy (41.2\%), Technology (13.4\%), Content (12.8\%), Technology/Pedagogy (11.3\%), Pedagogy/Content (5.7\%), Technology/Content (7.5\%), and TPACK $(8.1 \%)$.

Pedagogy was the most evident construct in every assignment because the pre-service teachers had so much to say about research-based teaching strategies. The pre-service teachers discussed technology and content because they were important parts of the lesson. However pedagogy was most evident because teacher candidates shared different strategies they could use to engage students, how to promote productive struggle, what a worthwhile task is, how to encourage a growth mindset, etc.

Some conclusions we can make from this data were that pre-service teachers showed a large amount of evidence of pedagogy knowledge with a total of 371 times where teaching strategies were addressed. Content knowledge was the second highest with 174 times, followed by technology at 153 counted usages of talking about their technology. Researchers concluded that pedagogy was discussed the most out of any other knowledge because there were a lot of ways to address good teaching strategies and a lot of different techniques to talk about. The technology and content may be a little more precise and direct with how that pre-service teacher wants to implement those ideas, but pedagogy is more abstract and can be talked about in many different ways.

The final graph illustrates how TPACK was developed comparatively over three years. There are several trends that are apparent within this graph. For example, 2018 had a spike in technology knowledge demonstrated. But over all three years, all constructs with technology seemed to have decreased. Also important to note, is that 2019 saw a spike in pedagogy knowledge demonstrated and content knowledge data was similar every year. The research team has yet to explore the potential causes of these trends but plan on discussing this important data point. Overall, there is a vast amount of evidence that shows TPACK was developed in the Elementary Education Math Methods Technology Integration Project.

\section{Qualitative Data Analysis}

Listed below are examples of direct quotes from students which provide an additional layer of data interpretation. Each qualitative phrase has a section underlined and a letter in front to show what TPACK construct is being exhibited within that statement. After each of the statements, the technology is identified, along with the form of data and the year. This data helped inform TPACK development among teacher candidates as they completed this project. Below are some examples of how different students integrated one, or multiple TPACK constructs into either the Padlet, lesson plan, handout, or reflection section of the assignment.

\section{T=Technology Knowledge $\quad P=P e d a g o g y$ Knowledge $\quad C=$ Content Knowledge}

T - "The Ozobot is a small robot that can follow lines, move freely, detect colors, and can be programmed using specific visual color codes" (Ozobot, Handout 2019).

C - "students can learn geometric concepts: drawing points, lines, line segments, rays, angles (right, acute, and obtuse) and perpendicular/ parallel lines" (Geogebra, Reflection 2019).

$\mathbf{P}$ - "This process of critical thinking and problem solving requires productive struggle, because there is not a right or wrong answer, instead there are multiple entry points and ways to solve this problem" (Lego WeDo 2.0, Lesson Plan 2019).

TP - "The technology project using the solar robot provides for the chance to integrate multiple curriculum goals into one activity which will benefit students as they have a hands-on learning experience" (Solar Robot, Lesson Plan 2019).

PC - "Then developing their understanding of shapes by visualization, analysis, deduction, and rigor as they classify and organize shapes" (WebQuest, Handout 2019).

CT - "be able to understand the difference between area and perimeter, calculate using formulas, and use Minecraft to measure both" (Minecraft, Lesson Plan 2019). 
TPACK - "We decided for the maker's movement lesson to have the students construct a house out of recycled material and find the perimeter for certain object on their house" (Maker's Movement, Reflection 2019).

TPACK - "Dash gives the students a chance to work together, think critically, problem solve, be flexible, and express creativity all while using math skills" (Dash Robot, Padlet 2019).

TPACK - "With this robot, technology is incorporated to encourage students to use problem solving, creativity, and computer coding, while practicing methods for perimeter and area" (Ozobot, Reflection 2019).

TPACK - "They [the students] will productively struggle when trying to decide which unit of measure [alternative measuring devices] would work best in a real-world scenario, because there isn't a set way to determine the answer and there is not one right answer" (Measurement Reflection 2019).

\section{Discussion}

TPACK integration can be beneficial to promoting meaningful learning and has the potential to help meet the needs of all learners in the classroom. This research confirmed this potential through the analysis of 1,028 data points of TPACK identified in pre-service teacher learning.

As previously mentioned, the data analysis for this research project determined that the most evident of the isolated TPACK constructs was pedagogy which answered the initial RQ1 research question: To what extent were each of the TPACK constructs developed in the Elementary Education Math Methods Technology Integration Project?

Researchers in this project hypothesized that pedagogy knowledge was most evident within the various components of this assignment because the instructional strategies are an important part to conceptualize when developing a thoughtful lesson plan. Another potential reason that teacher candidates might have shared a large amount of pedagogical knowledge is because teacher candidates are enrolled in a math methods course which shares best instructional practices in elementary math instruction in the class lectures as well as the required readings.

The research findings also provided answers to the second research question for this project, RQ2: What evidence of each of the TPACK constructs was found within the four assignments? The assignment requirement that demonstrated the highest amount of evidence of the various TPACK constructions were the final reflections. Each reflection required pre-service teachers to write about their learning and knowledge gained from the assignment experience. Data from the reflections demonstrated some of the highest rates of pedagogy knowledge (41\%), content knowledge (12\%) and TPACK cumulative knowledge (8\%). The reflections also provided detailed and descriptive qualitative data to inform the conclusions established by the quantitative analysis (see qualitative comments above). The quantitative numbers provided one perspective and the qualitative comments help inform and describe the pres-service experience, thoughts and feelings.

Researchers hypothesize that the final reflections demonstrated some of the largest evidence of TPACK constructs from the assignment for two reasons. To begin with, students were asked to respond to specific prompts that discussed TPACK and how it was developed throughout this semester-long project. Second, the reflections were completed at the end of the semester, after reviewing peer projects and therefore students had further developed their knowledge of TPACK.

\section{Limitations of Study}

Some limitations of this study were that it was conducted within one teacher preparation course with a sample size of about sixty students per year out of the 14,000 students enrolled on this campus. The data was only collected at one midwestern university in the math methods course. To strengthen the findings, the researchers have replicated the study over the course of three years, but to further strengthen the study, researchers would need to gather and look at data from multiple universities. Another important component of consideration for this study is that the students enrolled in this course were exposed to additional technologies which could have impacted their TPACK development levels because of the extra exposure to other technologies. For example, students enrolled in this course also were required to use at least three other technologies including the online video feedback program GoReact, a virtual learning environment which simulated an elementary classroom, along with various additional content specific iPad applications.

\section{Next Steps}

Important parts of a thorough research project are analysis, application and improvements. In a multi-yea study, it's tempting to tweak the project and make changes as you see which elements fit, provide better data or become important to the assignment. However, a conversation that we have had as a research team throughout the years is the importance of looking at data throughout the years and this means that data needs to remain somewhat consistent for comparison 
reasons. In determining the next steps, as a research team we have decided most often not to change the assignment too much beyond adding different innovative technologies over the years which didn't change our data at all.

Finally the only other significant change that we have made to the assignment most recently was moving from in-person presentations to video recorded as this was more time efficient and allowed teacher candidates to provide feedback to each other via the Blackboard discussion board. The discussion board became a vital part of the assignment because peers could provide detailed individualized feedback much better in this format than in person. Incorporating recorded presentations also added another level of technology integration because teacher candidates used a wide variety of presentation tools for this final step of the assignment.

\section{Conclusion}

In the 21 st century classroom, it is important that we acknowledge both the benefits and drawbacks with technology so pre-service teachers can evaluate the effectiveness of their instruction and student learning in the classroom. Incorporating technology into the classroom has the potential to help students feel less intimidated by a certain subject because learning is disguised in the form of a game, robots, or computer program. Technology allows teachers to scaffold student learning to individual student levels within the content. For instance, there are a multitude of entry and exit points when using technology because it can be adjusted to allow students to start and stop at various levels. In addition to that, these technologies can help students feel as though the content they are learning is more relevant to their everyday lives because students are digital natives and using different technologies throughout their daily lives outside of the classroom. Giving teachers new technology will not increase learning on its own. The understanding of the technology, aligning it with content and carrying out sufficient direction are integral parts of having a successful technology infused learning experience. Merging different content specific technologies with best pedagogy into the classroom has the potential to have a powerful impact on the "sweet spot" of elementary level learning.

In conclusion, it is evident that this project was a catalyst for pre-service teacher to successfully developing TPACK. Through a quantitative and qualitative analysis, pre-service teachers demonstrated the development of the three separate TPACK constructs, overlaps between the constructs, and the "sweet spot" of TPACK as a whole. This study highlighted why TPACK is important and how to develop TPACK in a teacher preparation course. This topic would benefit from further investigation because technology can be an advantageous tool if implemented correctly.

\section{References}

Bate, F. G., Day, L., \& Macnish, J. (2013). Conceptualising Changes to Pre-Service Teachers' Knowledge of How to Best Facilitate Learning in Mathematics: A TPACK Inspired Initiative. Australian Journal of Teacher Education, 38(5), n5. https://doi.org/10.14221/ajte.2013v38n5.3

Finger, G., Jamieson-Proctor, R., Cavanagh, R., Albion, P., Grimbeek, P., Bond, T., ... Lloyd, M. (2013). Teaching Teachers for the Future (TTF) Project TPACK Survey: Summary of the key findings. Australian Educational Computing, 37(3), 13-25.

Gür, H., \& Karamete, A. (2015). A short review of TPACK for teacher education. Educational Research and Reviews, 10(7), 777. https://doi.org/10.5897/ERR2014.1982

Herring, M. C., Mishra, P., \& Koehler, M. J. (2016). Handbook of technological pedagogical content knowledge (TPACK) for educators. New York, NY: Routledge. https://doi.org/10.4324/9781315771328

Hsu, P. S. (2012). Examining the impact of educational technology courses on pre-service teachers' development of technological pedagogical content knowledge. Teaching Education, 23(2), 195-213. https://doi.org/10.1080/10476210.2011.622041

Jamieson-Proctor, R., Albion, P., Finger, G., Cavanagh, R., Fitzgerald, R., Bond, T., \& Grimbeek, P. (2013). Development of the TTF TPACK survey instrument.

Keser, H., Yılmaz, F. G. K., \& Yilmaz, R. (2015). TPACK competencies and technology integration self-efficacy perceptions of pre-service teachers. Ilkögrretim Online, 14(4). https://doi.org/10.17051/io.2015.65067

Lee, Y., \& Lee, J. (2014). Enhancing pre-service teachers' self-efficacy beliefs for technology integration through lesson planning practice. Computers \& Education, 73, 121-128. https://doi.org/10.1016/j.compedu.2014.01.001

Lunenberg, M., Korthagen, F., \& Swennen, A. (2007). The teacher educator as a role model. Teaching and Teacher Education, 23(5), 586-601. https://doi.org/10.1016/j.tate.2006.11.001

Mack, N., Woodsong, C., MacQueen, K. M., Guest, G., \& Namey, E. (2005). Qualitative research methods: A data collector's field guide. Research Triangle Park, NC: Family Health International. 
Mishra, P., \& Koehler, M. J. (2006). Technological pedagogical content knowledge: A framework for teacher knowledge. Teachers College Record, 108(6), 1017-1054. https://doi.org/10.1111/j.1467-9620.2006.00684.x

Mouza, C., Karchmer-Klein, R., Nandakumar, R., Ozden, S. Y., \& Hu, L. (2014). Investigating the impact of an integrated approach to the development of preservice teachers' technological pedagogical content knowledge (TPACK). Computers \& Education, 71, 206-221. https://doi.org/10.1016/j.compedu.2013.09.020

Mudzimiri, R. (2012, July). A study of the development of technological pedagogical content knowledge (TPACK) in pre-service secondary mathematics teachers. Retrieved January 22, 2017, from http://scholarworks.montana.edu/xmlui/handle/1/1910

Niess, M. L. (2012). Re-Thinking Pre-Service Mathematics Teachers Preparation: Developing Technological, Pedagogical, and Content Knowledge (TPACK). In Developing Technology-Rich Teacher Education Programs: Key Issues (pp. 316-336). IGI Global. https://doi.org/10.4018/978-1-4666-0014-0.ch021

Niess, M. L. (2018). Scaffolding Subject Matter content with pedagogy and technologies in problem-based learning with the online TPACK learning trajectory. In Teacher training and professional development: Concepts, methodologies, tools, and applications (pp. 914-931). IGI Global. https://doi.org/10.4018/978-1-5225-5631-2.ch040

Saldaña, J. (2015). The coding manual for qualitative researchers. Thousand Oaks, CA: Sage.

Shulman, L. S. (1986). Those who understand: Knowledge growth in teaching. Educational Researcher, 15(2), 4-14. https://doi.org/10.3102/0013189X015002004

Tondeur, J., Van Braak, J., Sang, G., Voogt, J., Fisser, P., \& Ottenbreit-Leftwich, A. (2012). Preparing pre-service teachers to integrate technology in education: A synthesis of qualitative evidence. Computers \& Education, 59(1), 134-144. https://doi.org/10.1016/j.compedu.2011.10.009

Wetzel, K., Buss, R., Foulger, T. S., \& Lindsey, L. (2014). Infusing educational technology in teaching methods courses: Successes and dilemmas. Journal of Digital Learning in Teacher Education, 30(3), 89-103. https://doi.org/10.1080/21532974.2014.891877

Yigit, M. (2014). A review of the literature: How pre-service mathematics teachers develop their technological, pedagogical, and content knowledge. International Journal of Education in Mathematics Science and Technology, 2(1), 26-35. https://doi.org/10.18404/ijemst.96390

\section{Copyrights}

Copyright for this article is retained by the author(s), with first publication rights granted to the journal.

This is an open-access article distributed under the terms and conditions of the Creative Commons Attribution license (http://creativecommons.org/licenses/by/4.0/). 